\title{
The Color Application Research on Environment Art Design Based on the Analytic Hierarchy Process
}

\author{
Songxia Zou \\ Department of Art and Design \\ Chongqing Vocational Institute of Engineering \\ Chongqing, China
}

\begin{abstract}
Keywords: analytic hierarchy process; environment art design; color applications; weight vector
\end{abstract}
\begin{abstract}
As one of the elements of art design, the color has strong expressiveness and influence, and through the visual sense the people gradually generate a series of similar physical effects from the physiology to the psychology, the physical effects make people's subconscious constantly generate rich association to form profound meaning and symbolism. This paper focused on the color application of the environment art design, and analyzed the important role of color mixing and color toning of the environment art design, used the analytic hierarchy process to have depth analysis of color applications of the environmental art design, according to the combination of color weight vector it discriminated the importance in the environment art design to provide a new path for the theoretical research and practical performance of this field.
\end{abstract}

\section{Introduction}

The modern meaning of the environment design is the planning and design that carried out to meet the needs of the material environment that focuses on the space and generated for the good maintenance and the sustainable development of people's subsistence the social life. It is linked with human optimal matching activities, and it has a very broad activity field design and mainly includes architectural design, civil engineering, urban planning, environment engineering and so on[1]. There are a lot of researches in this field, for example, the green design concept on environmental art design that written by Wang Huiying had a combination with the green design concept of the traditional philosophy to thoroughly dissect the real content of green design, and summed up the basic principle of green design of environmental art design and put forward the specific and feasible methods of green design; the color application in the environment art design was written by Yuan Liguo and Li Junhua, it discussed the law of the harmonious color in environment art design, and made a statement from the meaning of color, the secondary sex characteristic of the color and the function of the color in the environment art design; the application of fast performance in environmental art design written by Chen Hongwei used a large number of fast performance charts as the example foundation to construct the framework of junior fast performance research, it combined the fast performance with the environment art design, explained the role of fast performance in the art design, thoroughly analyzed the basic types of the fast performance, and deeply discussed the speculative application of the fast performance in environment art design; the system theory of environment art design was written by Niu Jun[2], it used the analytical method of systems theory, based on the scientific concept of development, pursued the continuity and artistic value of environment space, the application of new materials in the science and technology, the reform of modern education system and other aspects of harmony, it had the detailed technical analysis and thorough research in the field of the environment art design; the application of the deconstruction and reconstruction of traditional color in the environment art design was written by $\mathrm{Hu}$ Xiang and $\mathrm{Xu}$ Huachun[3], it was through the introduction and analysis on the new design method that was the deconstruction and reconstruction of traditional color to combine with its application in environment art design, and it showed one side of the unique national cultural connotation in the design and enriched the language of expression of the art design; the essential factor in environment art design-color written by Zhang Youzhong[4] and the application of color in the environmental art design written by Peng Tao and Fu Pengfei both started from the functionality and the practicability of the environment art design, prominently performed the importance of aesthetic and effect of visual sense on the results of design performance, and emphasized the influence of color on the environmental art design. 


\section{The important role of color mixing and color toning in the environment art design}

In daily life, the color is everywhere, but we usually ignore its importance. In the environmental art design the color greatly satisfies the people's need for functionality and spirituality of the design. It uses the color's characteristics, the ingenious design technique and the matching rules to give the complete sense of art and design to the simple color, and it plays the charm of color to the greatest limit and lets the whole art design space show extraordinary talents. The preferences of people for various colors are also different[5]. The color mixing and color toning in the environment art design is to carry out environment art design to increase the work desire and work efficiency of people, and improve the working environment and atmosphere to reduce the pressure. The purpose of color mixing and color toning in the environment art design is shown in the following Figure.

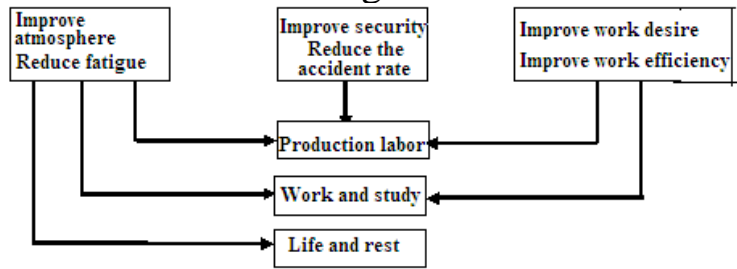

Figure 1. The purpose of color mixing and color toning in the environment art design

As shown in Figure 1, it gives full play to the role of the color mixing and color toning of environment art design in the production labor in order to make the people in the environment have full sense of space, dimensionality and distance, and it helped people form good transparency and explicit vocabulary in the color configuration to improve the work efficiency, improve the atmosphere, reduce fatigue, improve security and reduce the accident rate. Such as the design of the enterprises' working environment and leisure environment needs to notice lighting and illumination and avoid too strong light from making the person feel tired, its color needs to adjust color configuration rate to the best, it is shown as the following Figure.

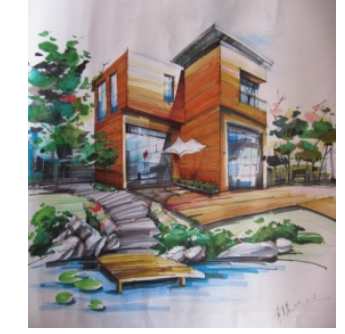

(a) Working environment

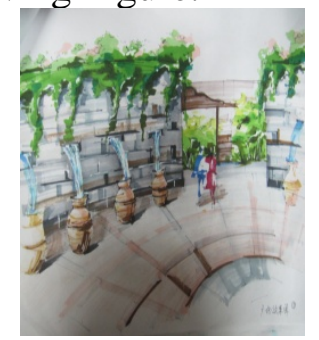

(b) Leisure environment

Fig. 2. The color toning in the design of enterprises' working environment and leisure environment

As shown in Figure 2 it paid attention to the light in the working environment, in the color collocation it didn't use dispirited, dull, dreary and dark color, and did not use a large area of dark gray, dark violet and so on, in the leisure place it focused on the dynamic water and simple green to make people relax, and the water movement took away the fatigue of the work[6]. In the design it should effectively use the situation that once people accept the foreign color stimulation, the perceptual experience can have certain echo with the foreign color stimulus and then generate some kind of mood.

Color is not isolated in environment, it is attached to the specific object and through the real object to express the color emotions; at the same time, color is also in the background color of the environment, and it makes all kinds of complicated situations in whole environment clear. In the outdoor space the adjustment of color needs to pay attention to the rich connotation of local culture and the influence of the night and other factors, it combines the static state with dynamic to produce the important role of the color mixing and color toning in environment art design. For example, in the environment art design of park it needs to pay attention to the park's main sense of hierarchy and the main crowd, its performance process is shown in the following Figure. 


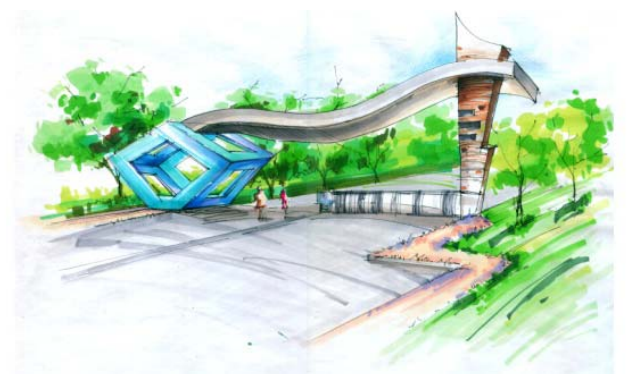

Figure 2. Sense of hierarchy of color in the park’s environment art design

As shown in Figure 3, in the entrance of the park, it chose bright blue in the trees to form harmonious color and tone. The reflection of the pink flowers in the roadside and the green becomes an interest, the theme and the hierarchy is clear and dynamic, so the entrance of the whole park does not appear weak, it does not have a strong contrast of the color.

Color is the charm of the environmental art design, there only has uncoordinated color combination, but there does not have the color that is no beautiful. The harmonious collocation of color refers to that it coincides with a person's mental state in a certain case and lets the person see the eyes color combination and feel cheerful. Therefore, it is important to cleverly use and better control all kinds of color in the environment art design.

\section{The application of hierarchy analysis on the color in environment art design}

Color does have the soul, it is the visual experience that accumulated by people in the long historical activities, and people give different emotion to the color. Color application in the environmental art design directly gives the color $x^{x}=\left(\begin{array}{llll}x_{1}, & x_{2} & \cdots & x_{n}\end{array}\right)^{T}$ of $n$ colors. If it is only limited to the mixture of the color's three primary colors and the addition, the $\boldsymbol{X}$ can be normalized and its calculation formula is[7,8]:

$$
w=\left(\begin{array}{llll}
w_{1}, & w_{2} & \cdots & w_{n}
\end{array}\right)^{T}=\left(\begin{array}{llll}
x_{1} / \sum_{i=1}^{n} x_{i}, & x_{2} / \sum_{i=1}^{n} x_{i} & \cdots & x_{n} / \sum_{i=1}^{n} x_{i}
\end{array}\right)^{T}
$$

In the equation (1), when $w_{i} \geq 0.5$, the bright color needs a strong hierarchy;

When $w_{i} \geq 1 / n$, the dark color also needs a strong hierarchy, and the $\boldsymbol{n}$ dimension vector $w=\left(\begin{array}{llll}w_{1}, & w_{2} & \cdots & w_{n}\end{array}\right)^{T}$ is a color weight vector;

When $w_{i} \geq 0$, and $\sum_{i=1}^{n} w_{i}=1$, it is used to describe the importance or intensity of the hierarchy of many colors levels, the $\boldsymbol{w}_{\boldsymbol{i}}(\mathbf{i}=\mathbf{1 . . n})$ is said as the weight of the first ${ }^{\boldsymbol{i}}$ color weigh vector[9]. As a result of the long-term visual experience, people have generated different reaction of different color in their psychology. Color is endowed with different symbols and meanings, so the associations and feelings of different people of the same kind of color are different. And there can give another form to describe color intensity of the $n$ color, the based data is $A=\left(a_{i j}\right)_{n \times n}$, and the component product

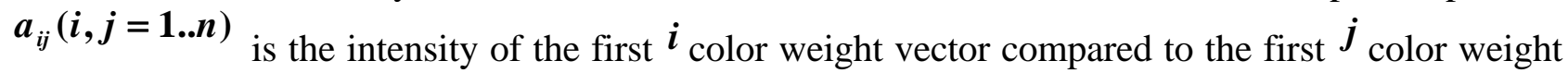
vector. Then the $\boldsymbol{A}$ is called as the paired comparison matrix. Because the component $\boldsymbol{a}_{\boldsymbol{i j}}(\boldsymbol{i}, \boldsymbol{j}=\mathbf{1 . . n )}$ is only involved the comparison of $\boldsymbol{i}$ and $\boldsymbol{j}$, this makes those who depend on people's subjective judgment to make a general quantity index become possible.

$w=\left(\begin{array}{llll}w_{1} & w_{2} & \cdots & w_{n}\end{array}\right)^{T}$ expresses the color weight vector of the $\boldsymbol{n}_{\text {color, }} \boldsymbol{A}=\left(\boldsymbol{a}_{i j}\right)_{n \times n}$ expresses the paired

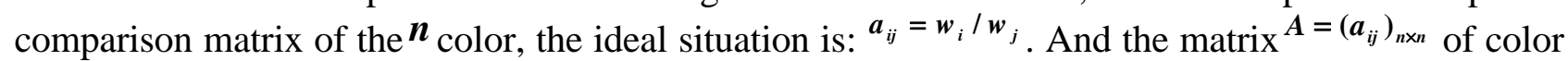
intensity of the $\boldsymbol{n}$ color meets the situations[10]:

A The intensity: ${ }^{a_{i j}>\mathbf{0}(i, j=1 . . n)}$;

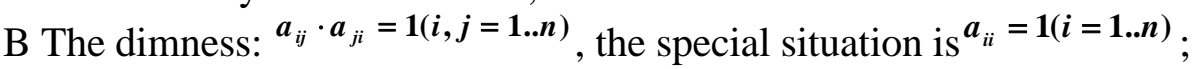

C The consistency: ${ }^{a_{i j}}=a_{i k} / a_{j k}(i, j, k=1 . . n)$. 
Obviously the consistency is more difficult to be grasped than the intensity, in the complex environment art design the color application should adopt multiple design scheme to have optimization decision, such as in the children's playground of the park, then it should use bright colors to create the child's attention and the interest of entertainment, at the same time it can't make the color and tonal too bright to stimulate the children. It is shown in Figure 4.

As shown in Figure 4, the environment art design of children's entertainment in the park pays attention to the collocation of color, the overall appears very appropriate and it suits the expectation of the kids and makes their entertainment happy. Such as the construction of color weight vector of the $\boldsymbol{n}_{\text {color and the paired comparison matrix }} \boldsymbol{A}=\left(\boldsymbol{a}_{i j}\right)_{n \times n}$, and the value of $\boldsymbol{a}_{i j}$ is in the numbers 1 to 9 and their reciprocal, these are the comprehensive considerations of the people's visual experience through the colors of all kinds of things in the nature, and they also psychologically form a certain mapping, for example, when people see the red color, they often think of the sun that has full energy and gives birth to everything, and the reverence feeling arises spontaneously; at the same time people can remember the flowing blood, this lets the person feel the existence of violence and brings uneasy feeling and so on[11]. When people see the green color, they remember the growth of plants and the hope and vitality. When people see the yellow color, they can remember mountains and plains of the sunflowers, and it is like the sunshine and full of energy and boil. Therefore, the color also becomes the essential element that can show people's inner emotions and reflect the thoughts and feelings. The compared measurement amplitude is limited in 1/9-9, the Table below gives the scale of value and meaning of $\boldsymbol{a}_{i j}$.

TABLE I. THE VALUE OF $\boldsymbol{a}_{i j}$ FROM THE NUMBERS 1 TO 9 AND THEIR RECIPROCAL

\begin{tabular}{|c|c|}
\hline The scale & $\begin{array}{l}\text { Meaning: } i \text { scheme (factor) is compared to } j \text { scheme } \\
\text { (factor) }\end{array}$ \\
\hline 1 & Equally important \\
\hline 3 & Slightly important \\
\hline 5 & Important \\
\hline 7 & Obviously important \\
\hline 9 & Absolutely important \\
\hline $2,4,6,8$ & Between the two adjacent level \\
\hline $1 / 2,1 / 3 \ldots 1 / 9$ & $\begin{array}{l}\text { Interchange the importance of } \boldsymbol{i} \text { scheme (factor) and } \boldsymbol{j} \\
\text { scheme (factor), it is applicable to the upper table }\end{array}$ \\
\hline
\end{tabular}

As shown in Table 1, in order to evaluate the degree of consistency of the color weight vector of

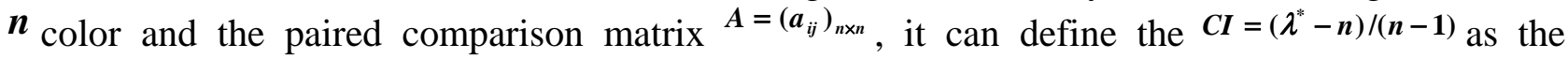
consistency index of $\boldsymbol{A}$, it is the opposite number of the average of the rest $\boldsymbol{n - 1}$ characteristic values except the $\lambda^{*}$, and it is close to 0 , the consistency of $\boldsymbol{A}$ is better. It is shown in Figure 5 .

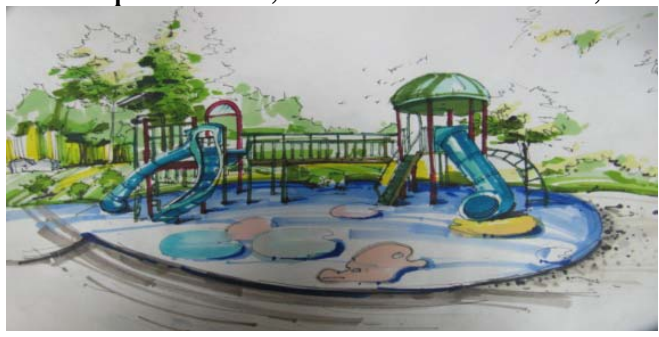

Figure 3. Environment art design of children's entertainment in the park

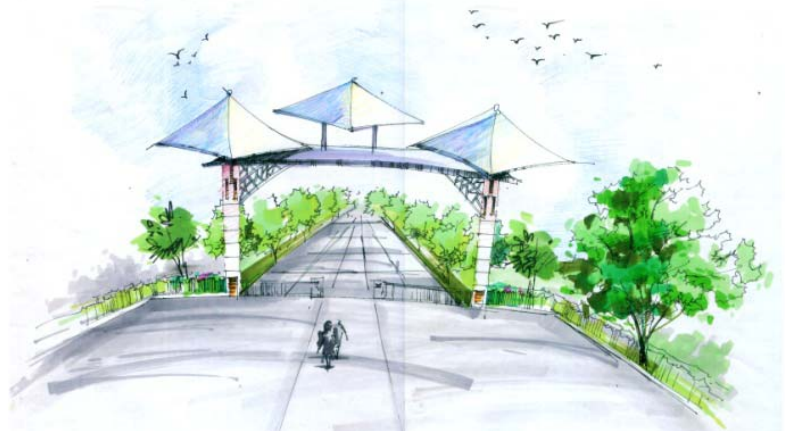

Figure 4. Consistency of color application hierarchy in environment art design

As shown in Figure 5, on the basis of the principle of color mixing it only used the color points of a few primary colors to organize a picture that is full of rich color feels and produce a pleasing visual and clear effect, and it became the model of color mixing space. That refers to that the color is not 
the absolute beauty or not beauty, its visual effect performance also depends on the shape or materials of the objects and their comprehensive color feeling, and the change of the relationship between color and light also makes the environment present different shade changes and style characteristics.

\section{Conclusion}

In the environment art design, because people's needs of the design works are complex and various, and the needs from the physical level to the spiritual level and from the physiological needs to the psychological needs and so on have high requirements. From the nature to people and people to social these three constitute elements that constructed the world we can see that the nature is the origin of life, with the development and the exploration of the nature people also strongly feel the influence of natural environment on the human existence, as well as the significance of the social progress. Along with the consciousness of people from "survival" to "environment", the modern people's consciousness is also from "survival consciousness" to a higher level of "environmental consciousness". The important role of the color mixing and color toning should be highlighted in the environment art design, and at the same we need to analyze the sense of hierarchy of the color application in environment art design.

\section{References}

[1] Wang Huiying. The green design concept on environment art design. Journal of Shandong agricultural management cadre institute,2012 (04): 56-59.

[2] Yuan Liguo, Li Junhua. The application of color in environmental art design . Era literature, 2009(01):31-33

[3] Chen Hongwei. The application of Fast performance in environment art design.Northeast forestry university,2008.

[4] Niu Jun.The environmental art design system theory.Tianjin university.2009.

[5] Hu Xiang, Xu Huachun. The application of deconstruction and reconstruction of traditional color in environment art design. Journal of Hunan engineering university (social science edition),2009(04):78-82.

[6] Zhang Youzhong. Essential factor of environmental art design-color .Science and technology consulting newsletter,2011 (11):107-111

[7] Peng Tao, Fu Pengfei. The application of color in environmental art design .China's new technology and new products,2010(13):45-49.

[8] Liu Huimin, Wang Donghui. Environmental art design color .Tsinghua university press, 2012:249-253.

[9] LuoYongyan. Planning and design of urban color environment.China architecture \&building press, 2007(11):63-67.

[10] Thompson. Visual psychology.China architecture \&building press, 2001:414-416.

[11] XiaoYihu. The Influence of Zen Culture on Chinese Art Design. Canadian Social Science,2012(2):5-12. 